\begin{tabular}{|c|c|c|c|c|c|c|}
\hline \multirow{4}{*}{ Impact Factor: } & ISRA (India) & $=3.117$ & SIS (USA) & $=0.912$ & ICV (Poland) & $=6.630$ \\
\hline & ISI (Dubai, UAE & $=0.829$ & РИНЦ (Russia & $=0.156$ & PIF (India) & $=1.940$ \\
\hline & GIF (Australia) & $=0.564$ & ESJI (KZ) & $=8.716$ & IBI (India) & $=4.260$ \\
\hline & JIF & $=1.500$ & SJIF (Morocco & $=5.667$ & OAJI (USA) & $=0.350$ \\
\hline
\end{tabular}

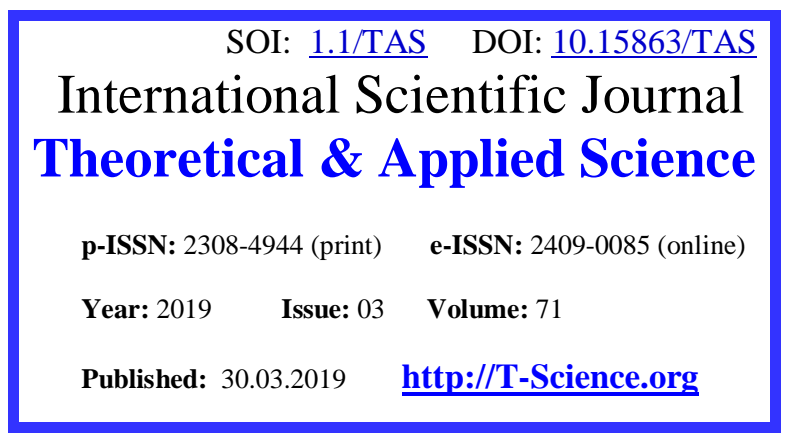

SECTION 21. Pedagogy. Psychology.

Innovations in the field of education.
QR - Issue

QR - Article

\title{
PROBLEMS OF ADAPTATION OF SCHOOLCHILDREN TO THE EDUCATIONAL PROCESS AT THE PRESENT STAGE
}

Abstract: In this paper we study the psychological characteristics of relationships with classmates and to adapt to classroom staff of primary school children. Shown that successful adaptation to classroom staff has a positive effect on psychological achievement pupils.

Key words: adaptation, school staff, the educational process, class, social status.

Language: Russian

Citation: Kazımova, G. S. (2019). Problems of adaptation of schoolchildren to the educational process at the present stage. ISJ Theoretical \& Applied Science, 03 (71), 573-576.

Soi: http://s-o-i.org/1.1/TAS-03-71-57 Doi: crossef https://dx.doi.org/10.15863/TAS.2019.03.71.57

\section{ПРОБЛЕМЫ АДАПТАЦИИ ШКОЛЬНИКОВ К УЧЕБНОМУ ПРОЦЕССУ НА СОВРЕМЕННОМ ЭТАПЕ}

Аннотация: В статье изучается психологически особенности взаимоотношений с одноклассниками и адаптации к классному коллективу младших школьников. Показано, что успешная адаптация к классному коллективу положительно влияет на психическое развитие и успеваемость младших школьников.

Ключевые слова: адаптация, школьньй коллектив, учебно-воспитательный прочесс, класс, сочиальный статус.

\section{Введение}

Младшие школьники в начале обучения, особенно первые месяцы сталкиваются ряда трудностями, среди, которых можно перечислить: смена ведущего вида деятельности т.е. замена игровой деятельности с учебной, адаптация к новому коллективу и сверстникам, которая требует много времени.

На сегодняшний день существует множество подходов изучающие проблемы адаптации к социальной среде среди которых, наиболее распространены три: а) адаптация в социальной среде через само изменение; б) адаптация социальной среды к себе; в) адаптация через самоизоляции от социальной среды.

Адаптация к социальной среде через само изменение представляет собой комфортность, согласие с требованием окружающих людей и условий. При этом, адаптация как попадание «Я» под влияние внешних воздействий. Неадаптированные доминирующими нормами и ценностями среды, или плохо адоптированные попадают в ряды аутсайдеров в группе. В эту категорию относятся большие творческие люди и одарённые дети.

Адаптация социальной среды к себе в сущности - это удовлетворения лишь потребностей и приспособления других к этому. Такая форма адаптации нацеливает на новаторское решение проблемы. Таким образом, постепенно образуется новая система норм и ценностей. Такая форма адаптации характерна знаменитым людям, обладающим силой воли, сильным характером. Такие люди выдвигают свои идеи, внушают их другим, умеют вести за собой других. Такая новаторская, творческая адаптация, в большинстве случаев, может быть полезно для больших групп, но для малых групп, педагогических коллективов она может оказаться малоэффективным.

Третья форма адаптации, адаптация через самоизоляции от социальной среды происходит тогда, когда не могут реализоваться предыдущие две формы адаптации. Так, что индивид не может 


\begin{tabular}{|c|c|c|c|c|c|c|}
\hline \multirow{4}{*}{ Impact Factor: } & ISRA (India) & $=3.117$ & SIS (USA) & $=0.912$ & ICV (Poland) & $=6.630$ \\
\hline & ISI (Dubai, UAE & $=0.829$ & РИНЦ (Russia) & $=0.156$ & PIF (India) & $=1.940$ \\
\hline & GIF (Australia) & $=0.564$ & ESJI (KZ) & $=8.716$ & IBI (India) & $=4.260$ \\
\hline & JIF & $=1.500$ & SJIF (Morocco & $=5.667$ & OAJI (USA) & $=0.350$ \\
\hline
\end{tabular}

достигнуть того, чтобы его мысли и желания были приняты окружающими, а также, затрудняется принять требования окружающих. В таком случае, изменяется отношение человека к ценностным системам, которых он одобряет и желает реализовать. Такая форма адаптации имеется обычно у творческих людей. Они оказываются не в состоянии изменить окружающую социальную среду, а так же. Не хотят принимать её в существующем виде. В таком случае они замыкаются в своём внутреннем мире, мир который полон фантазий. В своих фантазиях они выражают свои чувства и желания.

В младшем школьном возрасте в процессе адаптации и привыкании школьников друг к другу имеет особую роль общения их со сверстниками и взрослыми. В процессе общения друг с другом они выражают свои субъективные мнения, мысли и планы на будущее. В отличие от дошкольников в этом возрасте выдвигается на передний план, не действия и предметная деятельность, а общения. Младшие школьники также умеют учитывать потребности, желания, настроения других и умеют делать сознательный выбор. Это дает им возможность выбирать себе друга, товарища.

Психологи по разному подходят к проблеме адаптации личности в социальной среде, коллективу. М.И. Лисина отмечая особую роль общения, показывает, в процессе коммуникативной деятельности каждый из сторон участвует как субъект и как личность (6), а Д.И. Фельдштейн отмечает, что система отношений носит двойственный характер, одно из которых направлено к предметам другое к людям. Он считает, что находящиеся в единстве эти две системы отношений связаны с ведущим видом деятельности в разных возрастных периодах (3).

В психологической литературе описываются факторы, которые негативно влияют на процесс адаптации младших школьников к школьной жизни. В их ряду перечисляются следующие: снижение успеваемости; специфика возрастного развития (смена ведущей деятельности); неспособность произвольно управлять своим поведением, вниманием, учебной работой; неумение приспосабливаться к школьной жизни (2).

В первый класс дети приходят из различных семей, с отличительными особенностями, способностями и уровнем подготовки. Объединение их в едином коллективе, восприятие и понимание друг друга и на этой основе адаптация к классному коллективу так же, дальнейшее развитие и формирование их личности во многом зависит от того как организуется их учебно-воспитательная работа. Учебная деятельность как ведущий вид деятельности занимает главное место в психологическом развитии и адаптации младших школьников к классному коллективу. Поэтому, изучение в единстве их учебной деятельности и взаимоотношений имеет важное значение. Отношение младших школьников к себе и другим формируется в процессе игровой, учебной и трудовой деятельности, которые имеют огромные воспитательные значения.

C.A. Рубинштейн отмечает, что специфические особенности детей формируются в деятельности. Под руководством учителей они активно включаются в жизнь коллектива, развивают свою познавательную деятельность, усиливают знание и социальные нормы. (8).

Развивая идеи Л.С. Выгодского, Д.Б. Эльконин, В.В.Давыдов и Л.В.Занков приходят к выводу, что совершенствуя методы и содержания обучения можно ускорить психологическое развитие детей, изменить возрастные границы. Это означает, что психологическое развитие в значительной степени связано с учебной деятельностью.

Учебная деятельность имеет широкие возможности в процессе адаптации учеников к классному коллективу. В процессе учебной деятельности ученики усваивая научные знания также, приобретают знания в сфере взаимоотношений и навыки совместной деятельности.(5)

Исследователи (А.С.Байрамов, М.Г.Гамзаев, Р.И. Алиев, Л.И. Божович и др.) показывают, что обучение оказывается более эффективным когда имеет воспитательный характер. Если, тема урока позволяет формированию коллективистических мотивов и учитель умеет воспользоваться этой возможностью то тогда, изучаемая тема, служит также формированию личности младших школьников.

Практика показывает, что большинство учителей различия обучение и воспитание мало уделяют внимание воспитательной функции учебной деятельности. Последнее время уделяется большое внимание тому, что ученикам не следует давать готовых знаний, что обучение должно служить развитию мышления. А.А. Ализаде по этому поводу отмечает, что должно ориентироваться не к механической памяти, а логическому мышлению. Поэтому поводу он пишет: «Современная концепция об образовании оценивает эту проблему новыми мерками, заявляя её как одно из трех функций обучения и дает особое значение развитию теоретическому мышлению учеников. (1).

Ученики при выполнении учебных задач должны ссылаться не на конкретную ситуацию, а на способы общего решения их. В процессе развития теоретического мышления ученики больше ориентируются к коллективному решению проблем. Практика показывает, что введение дискуссий, полемики в процессе 


\begin{tabular}{|c|c|c|c|c|c|c|}
\hline \multirow{4}{*}{ Impact Factor: } & ISRA (India) & $=3.117$ & SIS (USA) & $=0.912$ & ICV (Poland) & $=6.630$ \\
\hline & ISI (Dubai, UAE & $=0.829$ & РИНЦ (Russia) & $=0.156$ & PIF (India) & $=1.940$ \\
\hline & GIF (Australia) & $=0.564$ & ESJI (KZ) & $=8.716$ & IBI (India) & $=4.260$ \\
\hline & JIF & $=1.500$ & SJIF (Morocco & $=5.667$ & OAJI (USA) & $=0.350$ \\
\hline
\end{tabular}

обучения повышает культуру общения учеников. Это положительно влияет на психическое развитие учеников, и они учатся работать в коллективе.

Проблема вхождения младших школьников в дискуссии и полемики, её влияние на их психическое развитие изучено недостаточно. Этот процесс должен находиться под руководством учителей. В младшем школьном возрасте, особенно в первом классе, ещё нельзя говорить о формирующемся коллективе, по тому, что они только начинают узнавать друг друга. Исследования показывают, что образования первого впечатления о других зависит и от объекта которого воспринимают и от психологической особенности субъекта, который воспринимает их. Первое впечатление также зависит от ситуации, в которой строится общение и от причин возникновения вербального и не вербального общения.

Восприятие и понимание друг друга в младшем школьном возрасте происходит на основе суждений других. Они выражают своё мнение о других в зависимости от конкретной ситуации и больше всего демонстрируют поведение в соответствии отношений взрослых. Потребность в общении с незнакомыми людьми и содержания общения у младших школьников возникает и происходит под влиянием внешних воздействий.(9)

Младшие школьники к специально организованному общению в учебной деятельности проявляют больше интереса. На уроках труда они разделяют своё внимание между трудовой деятельностью и наблюдением, происходящим в окружении. У первоклассников наблюдательность и навыки трудовой деятельности недостаточно сформированы, второклассники проявляют активность больше всего в процессе игровой деятельности, у третьеклассников в сравнении с первоклассниками и второклассниками внимание более гибкое и устойчивое.

Поведение младших школьников подчиняется ситуации деятельности. Так они ведут себя в соответствии с ситуацией, а это в свою очередь, создает условия для развития социальной установки.(10)

Анализ психологической литературы показывает, что в младшем школьной возрасте может различаться процесс восприятия и реальность. В большинстве случаев это зависит от ситуации и служит причиной неадекватному поведению. Негативное поведение их также, связано с наглядно-образным мышлением, который преобладает в этом возрасте.(7)

Восприятие и понимание лиц, с которыми человек впервые встречается, зависит от возрастных особенностей. Так первоклассники относятся к людям, которых встречают впервые дружелюбно, благородно, второклассники относятся к ним более выборочно. Их восприятие других зависит непосредственно от ситуации. Восприятие других людей у третьеклассников зависит от ряда факторов, главным образом от ситуации.

При описании людей, которых встречают первый раз, младшие школьники используют различные понятия. Первоклассники из - за того, что имеют достаточный словарный запас, применяют при этом также слова как «весёлый», «добрый», «хороший» и так далее, второклассники имеющие, уже значительный запас слов стараются выразить личностные качества и поведения людей такими словами как «заботливость», «внимательность», «хороший», «плохой» и т.д., а третьеклассники, имеющие уже достаточный запас слов выражают своё мнение более ясно и конкретно.

Адаптация младших школьников педагогическому коллективу, учебной деятельности, сверстникам, школьной жизни зависит от сложных, взаимосвязанных друг с другом факторов.(4) В зависимости от уровня адаптации к классному коллективу формируются у них личностные качества, создаются для достижения успехов и терпения неудач. Здесь играет немаловажную роль семейное воспитание, отношение родителей к школе. Изучения особенностей взаимоотношений младших школьников со сверстниками имеет особое значение. Социальный статус в классном коллективе, отношения одноклассников к нам значительно влияют на формирование поведенческих мотивов в этом возрасте. Всё это позволяет сделать вывод о том, что есть прямая зависимость между статусом младших школьников в классном коллективе. И уровнем адаптации к нему. В этом возрасте учителя должны учесть наряду с индивидуальными особенностями, также уровень адаптации их к школьному коллективу. Задачей учителей является обеспечение адаптации, к классному коллективу учитывая этих особенностей, воспитывая коллективизм и младших школьников. Практика показывает, что ряд учеников адаптируются к классному коллективу, коллективной деятельности легко и быстро, преследуя при этом личные интересы. Они активны, но эта активность направлена на то, чтобы отличиться от других, докажет своё преимущество над другими. Как правило, у таких учеников формирует самомнение самодовольствие.

Заключение

Обобщая вышесказанное можно сделать такой вывод, что между направленностью 


\begin{tabular}{|c|c|c|c|c|c|c|}
\hline \multirow{4}{*}{ Impact Factor: } & ISRA (India) & $=3.117$ & SIS (USA) & $=0.912$ & ICV (Poland) & $=6.630$ \\
\hline & ISI (Dubai, UAE & $=0.829$ & РИНЦ (Russia) & $=0.156$ & PIF (India) & $=1.940$ \\
\hline & GIF (Australia) & $=0.564$ & ESJI (KZ) & $=8.716$ & IBI (India) & $=4.260$ \\
\hline & JIF & $=1.500$ & SJIF (Morocco & $=5.667$ & OAJI (USA) & $=0.350$ \\
\hline
\end{tabular}

личности, мотивом поведения и уровнем адаптации младших школьников к классному коллективу есть прямая зависимость. Учёт этих особенностей позволяет учителям формировать коллектив и повысить качества обучения.

\section{References:}

1. Ali-zade, A. A. (1989). Psychological problems of the modern Azerbaijan school. Baku.

2. (1987). Communication and the formation of the personality of students. Experimental Experimental Psychological Research / Edited by A.A. Bodaleva, R.L. Krichevsky (Eds.). Nauch-issled. Institute of General and Pedagogical Psychology of the Academy of Pedagogical Sciences of the USSR. Moscow.

3. Feldstein, D. I. (1998). Psychology of personality development. Moscow.

4. Grishchenko, V. A. (2002). The desire for selfactualization as the most important factor in the success of the adaptation of displaced persons. (p.368). Moscow: In-ta Ethnol Publishing House. and anthropol. RAS.
5. Guliyev, Q. (2002). Study of Mutual Relations. Azerbaijan School, № 1, 79-81.

6. Lisina, M. I. (1986). Problems of communication ontogeny. Moscow.

7. Mardanov, M. Z. (2001). Azerbaijan's education reform path: success. problems, tasks. (p.130). Baku: Education.

8. Rubinstein, S. L. (1999). Basics of general psychology. Spb. Peter.

9. Sadigova, T. B. (2006). Possibilities and ways to use didactic games in the process of preparing children for school education: Ped. science moist ... dis. (p.159). Baku.

10. (1972). The study of the motivation of the behavior of children and adolescents. Ed. L.I.Bozhovich and L.V. Blugonadezhina (Eds). (p.352). Moscow: Pedagogy. 